\title{
Selecting the Parameters of The Diagnosis of Frame Insulation Condition in Electrical Machines of Locomotives
}

\author{
Michail Kapitsa $^{1 *}$, Vasiliy Laguta ${ }^{1}$, Yuriy Kozik ${ }^{1}$ \\ ${ }^{I}$ Dnipropetrovsk National University of Railway Transport named after Academician V. Lazaryan \\ *Corresponding author E-mail: vasilij.laguta@gmail.com
}

\begin{abstract}
The purpose of this study is to determine the signs displaying the insulation ageing process and allow predicting the change in its technical condition under operation of traction motors in locomotives. In order to choose the indicators of the insulation condition, the methods of linear electrical circuits were used to analyze the equivalent scheme of frame insulation. In the equivalent scheme, the dielectric micro- and macro-heterogeneities were taken into account. The most informative parameters of the frame insulation ageing process are those related to absorption and resorption processes over time. The return voltage has been selected as the main characteristic to determine the indicators of insulation condition. The analytical dependences for determining the frame insulation condition indicators have been obtained different from those currently used in the diagnosis of electrical machines. The choice of indicators will allow predicting changes in the technical condition of frame insulation in operation. The studies will allow us to change the regular preventive maintenance technology to the maintenance based on the facility condition.
\end{abstract}

Keywords: Absorption Current; Electrical Machine; Frame Insulation; Insulation Ageing; Return Voltage.

\section{Introduction}

One of the problems arisen in supporting the traction motors (TMs) is determining the ageing rate of the frame insulation and timely adopting measures to maintain its specified quality.

The insulation ageing changes in time the dielectric structure and affects the process of its destruction. In this connection, the intrinsic changes occur in the dielectric-relaxation behavior of the insulation structure. During the discharge in dielectric caused by a constant voltage, these relaxation processes lead to the occurrence of a relaxation current, which depending on the ageing mechanism has different time-current components that can be used for nondestructive evaluation of the TM insulation condition.

Current methods of the diagnosis of insulation condition in traction electrical machines of locomotives are ascertaining or destructive, but these methods do not give an overall picture of the actual dielectric condition.

Checking the TM frame insulation resistance with the use of special methods and equipment must be carried out regularly during operation. Having the knowledge of the deterioration of insulation over time, it is important to predict the reserve of its insulating ability in the future in order to prevent the TM sudden failure.

The unexpected removal of electrical machines from service is generally due to the deterioration of some essential components. Statistics show that over $50 \%$ of machine failures are due to insulation damage [1]. It is found that the insulation ageing is the most important factor that causes the insulation damage. The research of the insulation ageing has become an important concern to manufacturers and users of electrical equipment, in order to estimate the life reserve of the equipment. The ageing and degradation of electrical machine insulation are the phenomena that determine the lifetime of electrical machines in operation [2].
In (IEC 2011) it is shown that the ageing represents ,irreversible changes of the properties of an Electrical Insulation System (EIS) due to action by one or more stresses", [3]. For electrical machines and other equipment the diagnosis of the condition of insulating components becomes more and more important.

\section{Literature Review}

The insulation condition is characterized by a number of parameters which values are determined by the processes occurring in the dielectric (polarization, absorption, conductivity, etc.). These parameters include: dielectric characteristics of insulation (capacitance, dielectric loss factor); resistance; parameters related to absorption processes (change of resistance and capacity over time) [4-6].

The need to predict the TM insulation condition creates the prerequisites for determining the reasonable terms of preventive and regular maintenance and repairs. Such prediction should be expediently based on mathematical models of changes in the insulation condition. By now, the mathematical models of gradual deterioration of insulation have been developed, which allow predicting the change in its technical condition in real operating conditions [4-6]. The mentioned works describe some ageing insulation processes, but the user is often interested in the predicted moments of the frame insulation failure. The most complete description of the wear process of frame insulation and the methods for evaluating its condition are given in [7-9].

As shown the studies $[6,7,9,10]$, the most informative parameters of the frame insulation ageing process are those related to absorption processes (the processes of charging the inhomogeneous insulation with the accumulation of absorbed charge) and the resorption processes (the processes of measuring the return voltage caused by the release of absorbed charge) over time. 


\section{Materials and Methods}

\subsection{Main Indicators of Insulation Resistance}

Mainly checking the current condition of insulating materials is carried out using the values listed below [11].

Insulation resistance to direct current $R_{\text {ins }}$. The presence of coarse internal and external defects (damage, humidification, surface contamination) reduces the insulation resistance. The $R_{\text {ins }}$ is determined by measuring the leakage current passing through the insulation when the rectified voltage is applied to it.

The absorption ratio determines the insulation humidification. The absorption ratio is the ratio of the insulation resistance measured in 60 seconds after applying the voltage $(R 60)$ to the insulation resistance measured in 15 seconds $(R 15)$. If the insulation is dry, the absorption ratio is much greater than unity, while for wet insulation the absorption ratio is close to unity. The value of the absorption ratio should differ (downward) from the factory data by no more than $20 \%$, and its value should not be lower than 1.3 at a temperature of $10-30{ }^{\circ} \mathrm{C}$. If these conditions are not met, the product must be dried.

The polarization index shows the ability of charged particles to move in a dielectric under the influence of an electric field, which determines the degree of insulation ageing. The measurement method is based on a comparison of the megohm meter readings taken in 60 and 600 seconds after the start of the test.

The polarization index is characterized by the following indicators:

- less than 1 - the insulation is dangerous;

- between 1 and 2 - the insulation is doubtful;

- more than 2 - the insulation is good.

These indicators do not allow determining the ageing intensity of the frame insulation and directly determining the terms of its recovery.

\subsection{Quality Indicators of the Frame Insulation Condi- tion Based On Return Voltage}

The absorption rate for the frame insulation can be introduced similarly to the determination of the absorption rate for the dielectric

$U_{r e t}=k_{a} \cdot U_{\text {test }}$,

where $k_{a}$ is the absorption rate; $U_{\text {test }}$ is the test voltage; $U_{\text {ret }}$ is the return voltage - the maximum value during testing.

The absorption ratio shows how many times the maximum return voltage is less than the test voltage.

Taking into account the balance of energies accumulated in the insulation under the influence of the test voltage prior to and after the transition process, taking into account the macro- and microheterogeneity of the dielectric, [1] shows that the following relation is true for the absorption rate

$k_{a}=\frac{W_{r e s}}{W}$,

where $W_{\text {res }}$ is the residual energy after completion of the transition process in the insulation structure; $W$ is the total energy accumulated in the insulation structure due to the effect of the test voltage $U_{\text {test }}$.

Expression (1) sets the following physical content of the absorption ratio: the absorption ratio is the number indicating which part of the total energy stored in the insulation at macro- and micropolarization is returned during recovery. Another part of the ener- gy $W\left(1-k_{a}\right)$ is used for transferring the micro-particles and the macro-charges during recovery.

Suppose, that before starting to use the electrical insulation structure, it was found during the measurements that $U_{r e t}^{(1)}$ corresponds to the test voltage $U_{\text {test }}^{(1)}$. Let's consider that this test time is $t_{1}$. At this time

$k_{a}^{(1)}=\frac{U_{r e t}^{(1)}}{U_{\text {test }}^{(1)}}$

In some other period of insulation operation, which we assume the test time $t_{2}$, we have been obtained $U_{\text {ret }}^{(2)}$ for the test voltage $U_{\text {test }}^{(2)}$. If $U_{\text {test }}^{(1)}=U_{\text {test }}^{(2)}$ (the measurements were made under such conditions), then

$k_{a}^{(2)}=\frac{U_{r e t}^{(2)}}{U_{\text {test }}^{(2)}}$.

Absorption ratio subjected to $U_{\text {test }}^{(1)}=U_{\text {test }}^{(2)}$ is a constant value.

Let's introduce a new value

$S_{i n s}^{(1)}=\frac{k_{a}^{(1)}}{k_{a}^{(2)}}$.

Let's call this value an indicator of insulation condition. If $S_{i n s}^{(1)}=1$, then it means that during the operation period $\Delta t=t_{2}-t_{1}$ there was no change in the insulation.

If $S_{i n s}^{(1)}>1$, then this new value $S_{i n s}^{(1)}$ is a value indicating how many times the insulation condition deteriorated over time $\Delta t$ compared to the condition it has under the tests before putting into operation (for the time $t_{1}$ ).

For insulation structures of small capacity, the absorption ratio $k_{a}$ is usually used as an indicator of the change in the insulation condition.

During the operation, not only the value of the absorption capacity but also the insulation resistance $R$ varies. The change $R$ affects both the value of the absorption ratio $k_{a}$ and the value of insulation condition coefficient $S_{\text {ins }}^{(1)}$.

If the micro-polarization processes of absorption are neglected, then it is possible to adopt an equivalent scheme in which the absorption is simulated by the capacity $C_{a}$ and resistance $r_{a}$, Fig. 1. Mathematical simulation of the absorption process taking into account leakage currents allowed formulating the following indicator for the insulation condition of large-capacity structure.

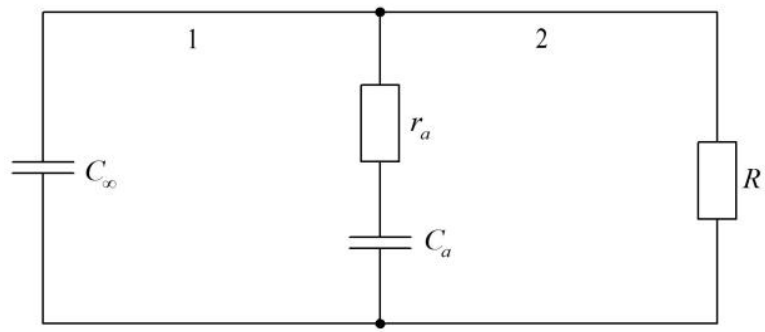

Fig. 1: Equivalent scheme used to consider the absorption process taking into account leakage currents.

In electrical machines with a large capacity of the frame insulation, the change in its condition may be determined by the rise time of the return voltage $t_{r}, U_{r e t}\left(t_{r}\right)=U_{r e t}^{\max }$, Fig. 2 . 
a)

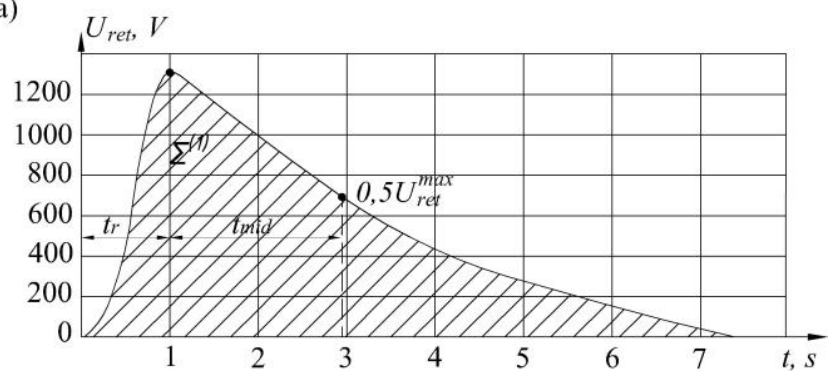

b)

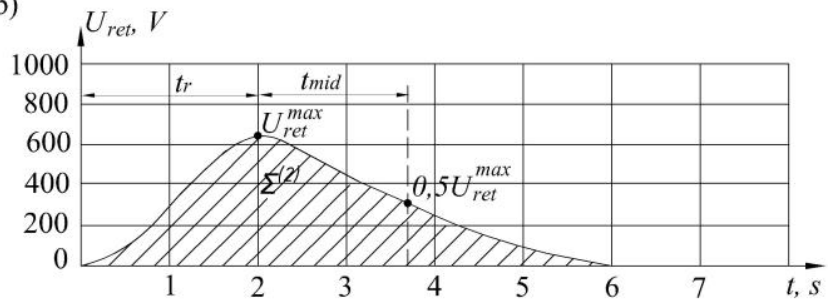

c)

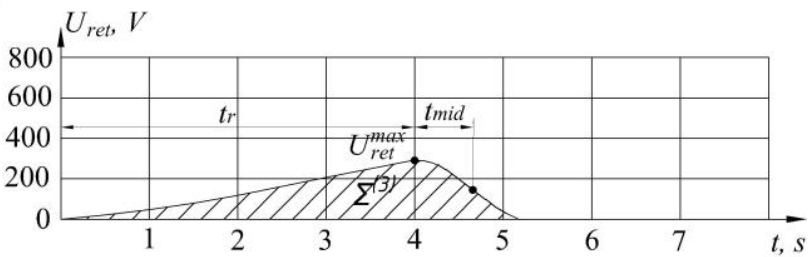

Fig. 2: Dependence of the return voltage value from its rise time and fall time: a) new insulation, TM mileage $L_{0} ;$ b) after a certain period of operation $L_{1} ;$ c) worn insulation, period of operation $L^{*}$.

It can be shown that insignificant change in the value of $C_{a} \cdot r_{a}$ under the constant value of $R$ will cause a significant change in the value of $t_{r}$. With the advent of lumped defects for largecapacity objects, the change $k_{a}$ will practically not be felt, and the process of voltage recovery will extend over time After $U_{\text {ret }}$ reaching a maximum, the self-discharge of capacity $C_{a}$ will begin.

During the operation, not only absorption capacity and absorption resistance but also insulation resistance varies. Therefore, changes in the macro-absorption and insulation resistance are best taken into account by the measurement of $t_{r}$. Change of insulation resistance during the operation can be assessed by another indicator of the insulation condition

$S_{\text {ins }}^{(2)}=\frac{t_{r}^{(2)}}{t_{r}^{(1)}}$,

where $t_{r}^{(1)}$ is the rise time of return voltage at the first measurement; $t_{r}^{(2)}$ is the rise time of return voltage at the next measurement during operation.

Another value characterizing an insulation condition is the value of the time $t_{\text {mid }}$ of self-discharge to the level of return voltage

$U_{\text {ret }}\left(t_{\text {mid }}\right)=0.5 \cdot U_{\text {ret }}^{\max }$

It makes sense to track the fall time of return voltage to the value $0.5 \cdot U_{\text {ret }}^{\max }$ during the test, because the change in both the dielectric heterogeneity and its resistance is estimated by the time of selfdischarge
$S_{\text {ins }}^{(3)}=\frac{t_{\text {mid }}^{(2)}}{t_{\text {mid }}^{(1)}}$

$S_{i n s}^{(3)}$ is an indicator evaluating the change in the insulation condition.

We can consider the area restricted by the curve of return voltage as an integral indicator of the insulation condition. Such an integral indicator is the most full and accurate characteristic of the current insulation condition. This criterion is based on comparing the area of accumulated energy of the new insulation, and the insulation that has already been in operation: $\Sigma^{(2)}$ and $\Sigma^{(1)}$, Fig. 2

\section{Results and Discussion}

Based on theoretical and experimental investigations of frame insulation in traction motors of locomotives, we have developed and manufactured a portable device, Fig. 3, capable to determine the frame insulation condition. With the aid of such device, it is also possible to diagnose the insulation condition of power electric cables, insulation of transformers, etc.

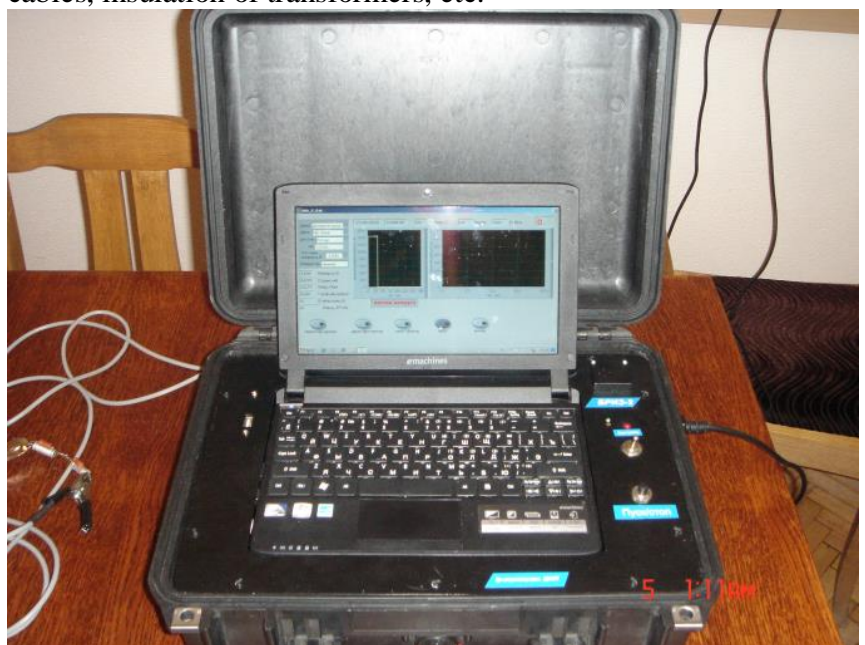

Fig. 3: Device for assessing the frame insulation condition in electrical machines of locomotives.

Basic requirements for the device:

- the signal protection from external and internal factors;

- the minimum value of the error of received signal (parameter value);

- the parameter reliability and informational content;

- availability in obtaining the parameter;

- the parameter measuring process must not adversely affect the insulation condition;

- minimum possible time for measuring the parameter;

- easy processing and visibility of received information;

- self-contained system for conducting studies and simple in maintenance;

- system safety.

You can use the device to get the following information: leakage current; insulation resistance; value of return voltage; rise time and fall time of return voltage; amount of accumulated energy - integral indicator; absorption ratio; air humidity; air temperature.

The self-containing feature of the device makes it possible to perform the necessary measurements directly on the locomotive during maintenance and repair, as well as in locomotive repair plants. Application of the device gives the following advantages:

- the ability to detect insulation defects in the early stages of their appearance;

- no need for long-term and energy-consuming tests;

- no need to use the lifting equipment for moving TMs to the testing site; 
- ability to equip TMs with suitable anchors and magnetic systems during repairs;

- the ability to store information for each anchor (magnetic system) and overall TM;

- no premature destruction of TM insulation.

Device specifications:

- output voltage [V]

$500-1500$

- current strength [mA]

10 ;

- overall dimensions [mm]

$200 \times 300 \times 300$

4.5 ( 2.3 without a battery).

- weight $[\mathrm{kg}]$

microprocessor components; it

provides interoperability with a portable computer that controls test modes (stand-alone, programmed). The experiments were conducted on NB-406 and ED-107 TMs. Fig. 2 shows testing results of NB-406 traction motors. The discrete values of measured return voltage were approximated by the cubic spline method without taking into account the derivative values at the beginning and end of the observation interval.

The device was tested in the Laboratory of Locomotives of the Dnipropetrovsk National University of Railway Transport. A screenshot of the device during the test of the TM frame insulation is in Fig. 4. Processing of measurement data is carried out in real time. The left window of the screenshot shows the test voltage, which is connected to the frame insulation, in the right window the corresponding return voltage curve is depicted.

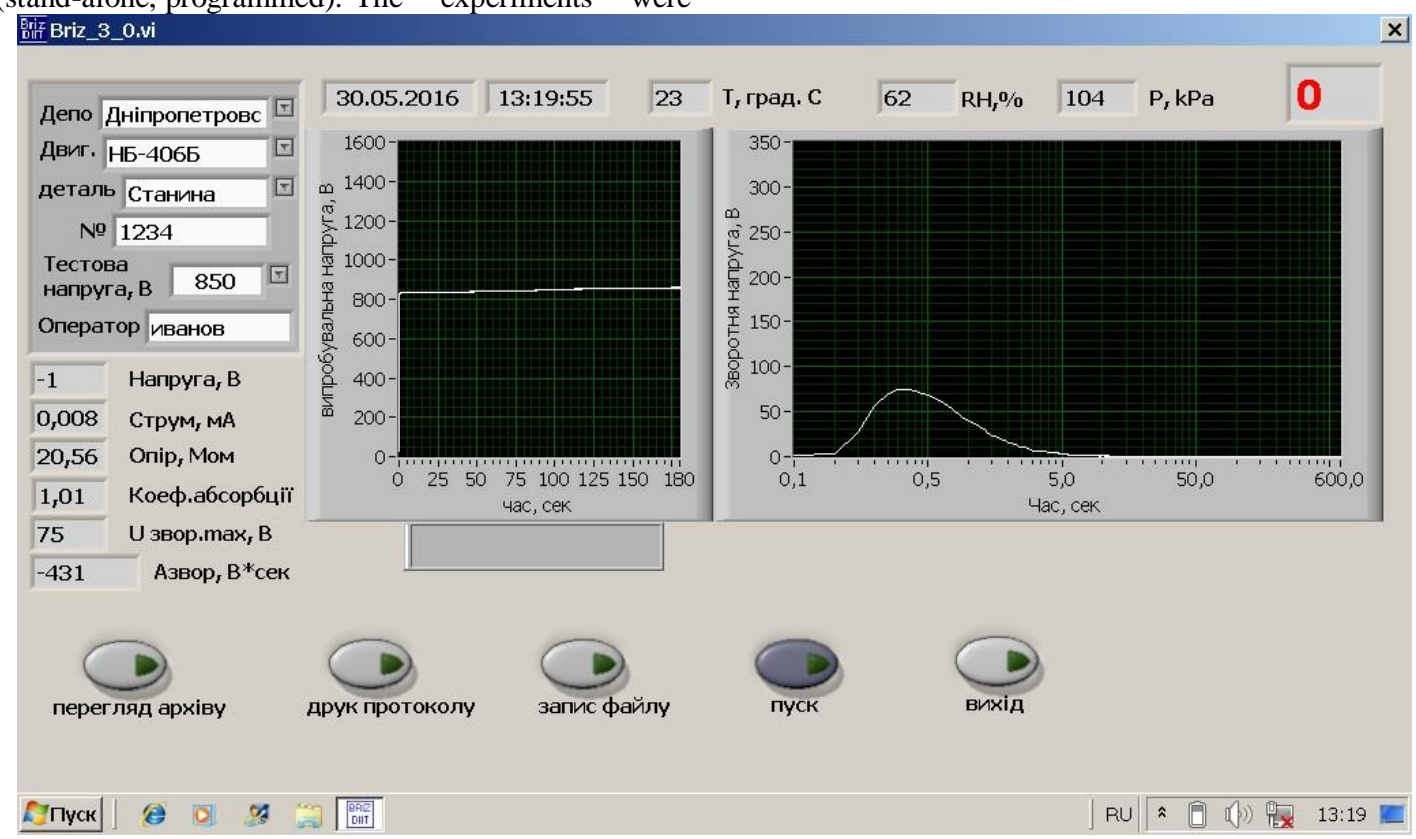

Fig. 4: Scanning of the device screen: test voltage (left), return voltage (right)

The application of the developed system for assessing the quality of frame insulation makes it possible to assess the current insulation condition, to automate the collection, logging, processing and analysis of current diagnostic information obtained during the testing of insulation. With the help of the proposed system, it is possible to create a data sheet containing necessary parameters for each individual TM.

\section{Conclusion}

The degree of internal field inhomogeneity for low-capacity objects can be estimated by the absorption ratio. In such cases, the insulation resistance is significant. In this case, we can take the value $S_{i n s}^{(1)}$ as an indicator of the electrical strength of insulation.

In case of high-capacity insulating structures (for example, when assessing the insulation condition of electric machines), the use of absorption ratio is inefficient. The value of $S_{\text {ins }}^{(1)}$ characterizes only the change of insulation macro-condition in the average. The change of insulation resistance, for example caused by humidification, is barely noticeable for the value of $k_{a}$.

Changes in the macro-absorption and insulation resistance may be taken into account by the measurement of $t_{r}$ (the time over which the return voltage reaches the maximum value). The change of insulation resistance during operation (reduction of electrical strength) should be estimated by the indicator $S_{i n s}^{(2)}$.

The change in the insulation heterogeneity and its resistance can be traced by an indicator $S_{i n s}^{(3)}$ that depends on the time of self- discharge $0.5 \cdot U_{r e t}^{\max }$, but this indicator is equivalent to the indicator $S_{\text {ins }}^{(2)}$

Estimation of the insulation condition by the ratio $R_{1} / R_{2}-$ (where $R_{1}$ is the insulation resistance at the first test, and $R_{2}$ is the value obtained at the next measurement) is not efficient. The value of insulation resistance is strongly dependent on the heterogeneity of the internal and external fields of the electrical insulation structure.

The area restricting the curve of the return voltage can be used as an integral indicator of insulation strength, which the most fully characterizes the current insulation condition.

The studies have been carried out in accordance with the Government Program of the Strategic Development of the Railways of Ukraine and the Program of Upgrading the Railway Traction Rolling Stock until 2020.

\section{Acknowledgement}

The research presented in this article made to order and funded by Pridniprovska Railway Company, Ukraine.

The authors are grateful to the management of the Depo Nizhnedniprovsk-Uzel engineering department for their assistance in obtaining the necessary data for research.The authors also express their gratitude to V.M. Lyashuk (Associate Professor, Dnipropetrovsk National University of Railway Transport) and V.M. Zubenko (the engineer of the testing center of Pridniprovska Railway Company) for assistance in creating a device for diagnosing the state of the TM frame insulation. We want to thank the post-graduate of the Locomotive Department A.E. Desyak for help in creating the drawings. 


\section{References}

[1] Rusu-Zagar C, Notingher PV, Stancu C, "Ageing and degradation of electrical machines insulation", Journal of International Scientific Publications: Materials, Methods and Technologies, Vol. 8, (2014). pp. 526-546, available onine: http://www.scientificpublications.net, last visit: 20.11.2017

[2] Rusu-Zagar, C, Notingher, PV, Navrapescu V, Mares G, RusuZagar G, Setnescu T \& Setnescu R, "Method for Estimating the Duration of Life Insulation of Electric Motors", Proceedings of $8^{\text {in }}$ International Symposium on Advanced Topics in Electrical Engineering, Vol. 3, (2013), pp. 1-6.

[3] IEC 60505 Ed. 4.0 b:2011. Evaluation and qualification of electrical insulation systems. International Electrotechnical Commission. pp. 9-31.

[4] Kapitsa MI, "Development of scientific base for improving the systems of traction rolling stock operation", Thesis for a degree of Dr. Sci. in Engineering, Dnipropetrovsk, (2010), pp. 168-224

[5] Privalov EE, Diagnostics of external insulation of electrical equipment: tutorial, Direct Media, (2015), pp. 32-40

[6] Lachin VI, Solomentsev KYu, Chi NQ, "Influence of absorption currents on the measurement of insulation resistance", Proceedings of XIII International Scientific and Practical Conference, Novocherkassk, April 23, (2013), pp. 31-33

[7] Patsch R, Kamenka D, Menzel J, "Return voltage measurements. Diagnostic interpretations based on the dielectric time constants", Materials Science-Poland, Vol.27, No.4, (2009), p.1157-1169.

[8] Kapitsa MI, Laguta VV, "Application of mathematical modeling to the estimation of the residual resource of electrical machine insulation", Proceedings of International Scientific and Engineering Conference, Sevastopol, September 8-14, Vol. 3, (2003), pp: 279-283

[9] Gavrilă DE et al., "Applying the Recovery Voltage Method (RVM) to Study the Degradation of High Power Transformer Insulation", Advanced Materials Research, (2014), Vol. 911, pp. 260-265

[10] Lachin VI, Solomentsev KYu, Chi NQ, "The influence of the absorption current on the process of measuring the insulation resistance", News of Higher Educational Institutions. North Caucasian Region. Engineering Sciences, No. 6, (2013), pp. 32-35

[11] Sonel SA, Measurement of electrical insulation quality parameters. http://www.sonel.ru/ru/biblio/article/isolation/. Revised March 2012. Accessed June 26, 2018 